\title{
STUDI PELUANG EFISIENSI KONSUMSI ENERGI LISTRIK DI PT. SAI APPAREL SEMARANG
}

\author{
Ahmad Taufik Yunanto*), Jaka Windarta, dan Susatyo Handoko \\ Departemen Teknik Elektro, Universitas Diponegoro \\ Jl. Prof. Sudharto, SH, Kampus UNDIP Tembalang, Semarang 50275, Indonesia \\ ${ }^{*}$ e-mail: ataufiky@gmail.com
}

\begin{abstract}
Abstrak
Ketahanan energi nasional memiliki peran yang sangat penting dalam mendukung pembangunan nasional yang berkelanjutan. Akan tetapi yang sering menjadi permasalahan adalah laju ketersediaan energi yang tidak seimbang dengan laju kebutuhan energi, maka dari itu perlu dilakukan efisiensi konsumsi energi pada sisi pemanfaat. Sektor industri menjadi konsumen energi listrik terbesar di Indonesia. Pada penelitian ini penulis akan melakukan analisis potensi efisiensi energi dengan mengangkat studi kasus pada salah satu industri garmen di kota Semarang, yaitu PT. SAI Apparel. Analisis efisiensi energi akan didasarkan pada data konsumsi energi dan produksi selama tahun 2016, serta evaluasi data pengukuran kualitas daya listrik. Berdasarkan hasil analisis kualitas daya listrik PT. SAI Apparel diketahui beberapa besaran kualitas daya listrik PT. SAI Apparel memiliki nilai yang tidak sesuai dengan standar dan berisiko meningkatkan rugi daya. Melihat kondisi tersebut didapatkan tiga rekomendasi penghematan energi yang dapat diimplementasikan di PT. SAI Apparel, yaitu penyeimbangan beban fasa RST untuk mereduksi ketidakseimbangan arus dan ketidakseimbangan tegangan, penggantian lampu TL dengan lampu LED akan menghasilkan penghematan energi sebesar 449.687kWh/tahun, penggantian mesin jahit motor induksi dengan motor servo akan menghasilkan penghematan energi sebesar $616.223 \mathrm{kWh} /$ tahun, dan perbaikan faktor daya akan menghasilkan penghematan daya sebesar $5.774,5 \mathrm{kWh} / \mathrm{tahun}$.
\end{abstract}

Kata kunci: Konservasi energi, Efisiensi energi

\begin{abstract}
National energy stability has a very important role in support of the national development sustainable. However, the problem is often the rate of energy availability not balanced with the rate of energy needs, therefore it is necessary to do the efficiency of energy consumption on the user side. The industrial sector becomes the largest energy consumer in Indonesia. In this study author will conduct analysis energy efficiency potential by raising a case of study on one of the garment industry in semarang, namely PT. SAI Apparel. The energy efficiency will be based on production and energy consumption data during 2016, and evaluate the measurement of the electrical power quality. Based on the analysis of electrical power quality of PT. SAI Apparel is known some quantity of power qualitsy of PT. SAI Apparel has values that are not in accordance with the standards and risk increase the loss of power. Seeing these conditions obtained three energy saving recommendations that can be implemented at PT. SAI Apparel, that is.RST phase load balancing to reduce voltage and current imbalance, replacement of TL lamp by using LED lamp will produce energy saving $449.687 \mathrm{kWh} / \mathrm{year}$, replacement sewing machine induction motor with servo motor will produce energy saving $616.223 \mathrm{kWh} / \mathrm{year}$, and improvement of the power factor will produce energy savings $5.774,5 \mathrm{kWh} / \mathrm{year}$.
\end{abstract}

Keywords: Energy Conservation, Energy Efficiency

\section{Pendahuluan}

Ketahanan energi memiliki peran yang sangat penting dalam mendukung pembangunan nasional yang berkelanjutan. Akan tetapi yang sering menjadi permasalahan adalah laju ketersediaan energi yang tidak seimbang dengan laju kebutuhan energi. Maka dari itu untuk mempertahankan ketahanan energi nasional selain giat melakukan pembangunan serta diversifikasi di sisi penyediaan sumber energi, upaya konservasi energi di sisi pemanfaatan untuk menekan laju penggunaan energi harus dilakukan.

Efisiensi energi atau penggunaan energi yang efisien bertujuan untuk mengurangi jumlah energi yang dibutuhkan untuk menghasilkan suatu produk atau layanan[1]. Pemerintah dalam PP No 70 Tahun 2009 telah mengatur bahwa pengguna sumber energi dan pengguna energi yang menggunakan sumber energi dan/ atau energi lebih dari 6.000 TOE (Tonne Oil Equivalent) dalam satu tahun wajib melakukan konservasi energi melalui 
manajemen energi, selain itu untuk pengguna sumber energi dan/ atau energi di bawah 6.000 TOE (Tonne Oil Equivalent) per tahun wajib menggunakan energi secara hemat dan efisien[2].

Pada penelitian ini penulis mengangkat studi kasus pada salah satu industri garmen di kota Semarang, yaitu PT. SAI Apparel. Konsumsi energi total pada PT. SAI Apparel selama tahun 2016 mencapai 4.815 TOE (tonne of oil equivalent). Karena konsumsi energi PT. SAI Apparel selama tahun 2016 kurang dari 6.000 TOE (tonne of oil equivalent) PT. SAI Apparel belum memiliki kewajiban untuk melakukan konservasi energi melalui manajemen energi, akan tetapi PT. SAI Apparel tetap memiliki kewajiban untuk mengkonsumsi energi secara hemat dan efisien. Dari data sampling Automatic Meter Reading milik PT. SAI Apparel, selama bulan juli tercatat setiap harinya terdapat nilai faktor daya di bawah 0,85 . Selain itu dari data tagihan rekening listrik PT. PLN (Persero), PT. SAI Apparel terkena penalti kVARH pada bulan november 2016 hingga januari 2017[3]. Masih terdapat peluang pemborosan energi yang tidak disadari oleh pihak perusahaan, maka dari itu dalam penelitian ini penulis akan melakukan identifikasi peluang efisiensi energi listrik yang dapat diimplementasikan di PT. SAI Apparel

\section{Metode}

\subsection{Metode Penelitian}

Pada Gambar 1 dapat dilihat langkah-langkah metode penelitian dalam penelitian ini.
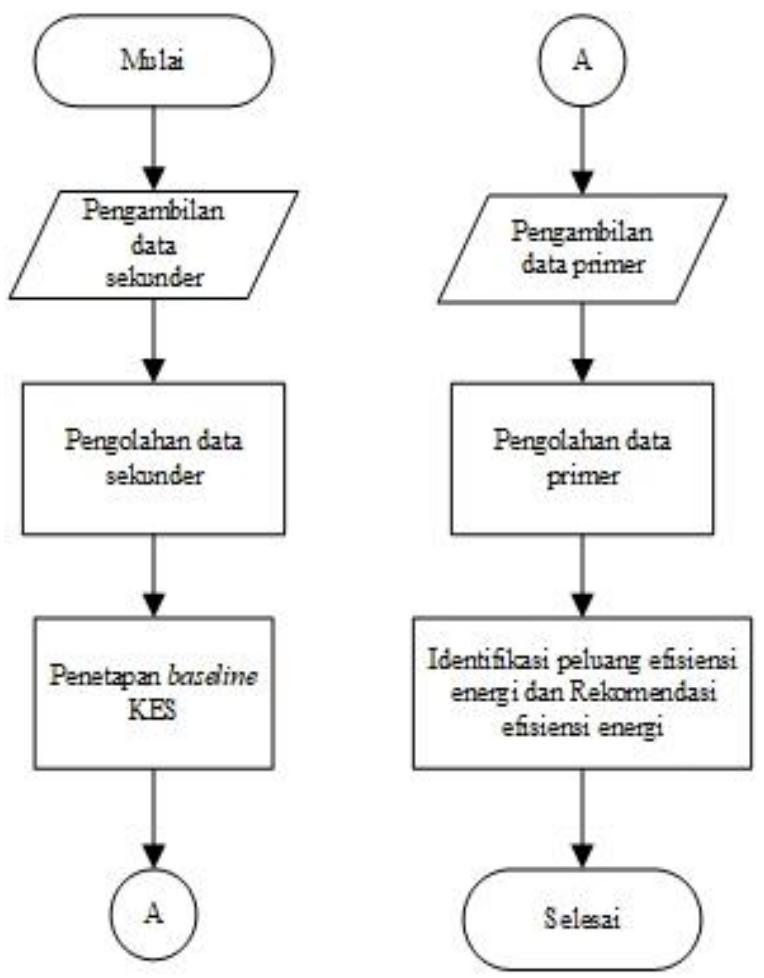

\subsection{Gambaran Umum Objek Penelitian}

PT. SAI Apparel adalah sebuah perusahaan garmen yang berdiri sejak tahun 1998. Beralamatkan di Jl. Brigjend Sudiarto km. 11 Semarang, Jawa Tengah, Indonesia. Dalam kegiatan produksinya PT. SAI Apparel menggunakan tiga jenis sumber energi yaitu energi listrik sebesar $2.770 \mathrm{kVA}$ sebagai sumber energi bagi mesinmesin produksi, energi batu bara sebagai bahan bakar boiler untuk menghasilkan steam, dan yang terakhir adalah energi solar sebagai bahan bakar genset apabila kondisi listrik padam. Proses produksi yang dilakukan di PT. SAI Apparel ditunjukan pada Gambar 2.
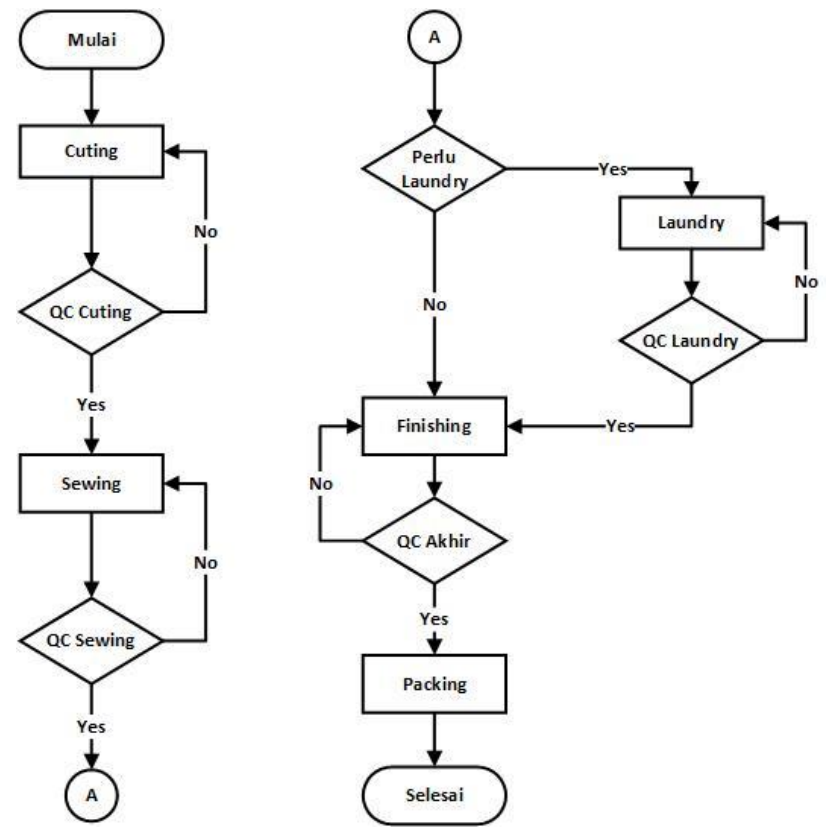

Gambar 2. Diagram Alir Produksi

\subsection{Data Penelitian}

Data penelitian terdiri dari data sekunder dan data primer. Data sekunder antara lain berupa data historis konsumsi energi, jumlah produksi selama tahun 2016, dan data Automatic Meter Reading PT. SAI Apparel. Selain data sekunder terdapat juga data primer berupa data hasil pengukuran kualitas daya listrik di PT. SAI Apparel. Distribusi tenaga listrik di PT. SAI Apparel menggunakan empat buah transformator distribusi. Pengambilan data primer dilakukan pada ke-4 substation tersebut. Data primer yang diambil antara lain sebagai berikut:

- Data arus dan tegangan masing-masing fasa

- Distorsi harmonik total arus dan tegangan

- Faktor daya

- Beban masing-masing substation

Gambar 1. Diagram Alir Penelitian. 


\subsection{Alat Ukur}

Dalam pengambilan data penulis menggunakan Power Quality Analyzer untuk melakukan record data di sisi LVMDP dan MDP. Pengukuran di MDP dan beban dilakukan menggunakan Clamp Hi Tester. Dalam kondisi pengukuran tidak dapat menggunakan kedua alat tadi, pengukuran arus dan tegangan dilakukan menggunakan tang ampere dan multimeter digital.

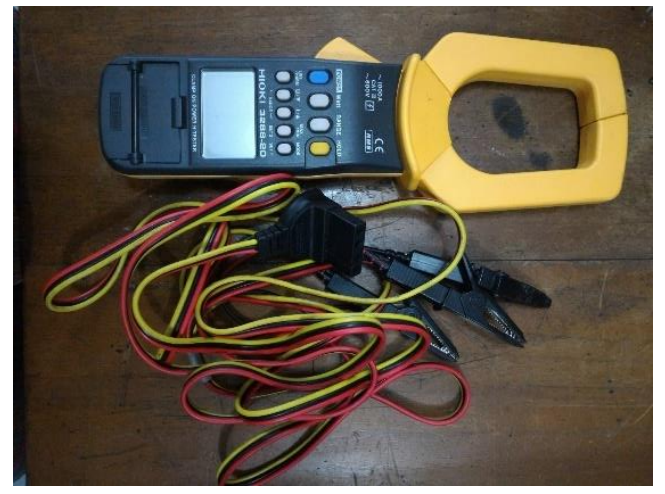

Gambar 3. Clamp Hi Tester Hioki

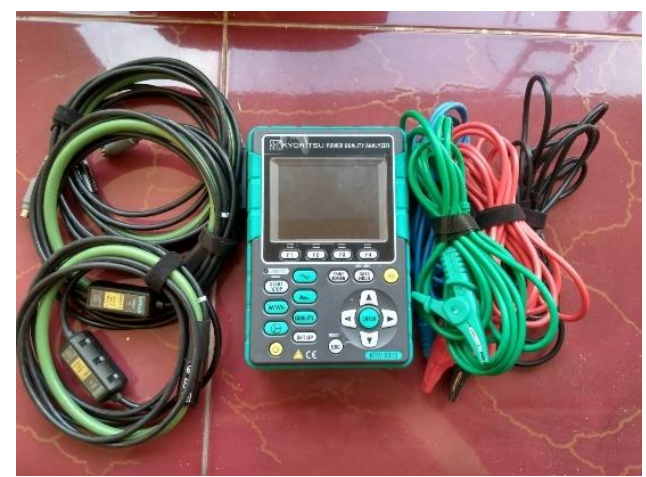

Gambar 4. Power Quality Analyzer

Untuk menjamin keselamatan, selama pengambilan data penulis selalu menggunakan Alat Pelindung Diri.

\subsection{Prosedur Pengambilan Data}

Pengambilan data dilakukan pada beberapa tempat, dengan prosedur sebagai berikut:

1. LVMDP, pengambilan data dilakukan selama satu jam menggunakan PQA meter. Data yang diambil dengan PQA meter adalah data tegangan dan arus masingmasing fasa, DHT arus dan tegangan. Selain itu dilakukan juga pengukuran menggunakan clamp $h i$ tester selama lima menit dengan durasi pengukuran dua belas jam dan jeda pengambilan data setiap satu jam. Data yang diambil adalah data beban. Selain itu dilakukan pembacaan nilai faktor daya pada cosphi meter digital panel LVMDP.
2. MDP, pengambilan data dilakukan selama satu jam menggunakan PQA meter karena arus pada beberapa LVMDP melebihi kemampuan alat ukur (1.000A). Data yang di ambil adalah data tegangan dan arus masing-masing fasa, DHT arus dan tegangan. Selain itu dilakukan juga pengukuran menggunakan clamp hi tester selama lima menit dengan durasi pengukuran dua belas jam dan jeda pengambilan data setiap satu jam. Data yang diambil adalah data beban.

3. SDP, dilakukan pengukuran beban menggunakan clamp hi tester. Selain pengukuran beban pada beberapa SDP dilakukan sampling pengambilan data tegangan.

4. Beban, pengukuran disisi beban menggunakan alat ukur clamp hi tester untuk mengetahui konsumsi daya aktual beban.

\subsection{Pengolahan Data}

Data yang telah diperoleh kemudian diolah untuk kemudian dianalisis. Data konsumsi energi dan jumlah produksi PT. SAI Apparel selama tahun 2016 digunakan untuk mencari bauran energi, profil beban, dan konsumsi energi spesifik PT. SAI Apparel selama tahun 2016. Data primer yang diperoleh dari pengukuran diolah untuk mencari:

- Pengguna energi spesifik (PES)

- Faktor pembebanan dan efisiensi trafo

- Ketidakseimbangan arus dan tegangan

- DHT arus dan tegangan

- Faktor daya masing-masing substation

- Susut tegangan

Hasil pengolahan data tersebut diatas kemudian dianalisis untuk mengetahui potensi pemborosan energi yang dihasilkan, dan mengidentifikasi peluang efisiensi energi yang dapat diimplementasikan.

\subsection{Identifikasi Peluang Hemat Energi dan Rekomendasi Efisiensi Energi}

Hasil pengolahan data dianalisis berdasarkan nilai standar efisiensi yang berlaku untuk data tersebut. Semua peralatan yang terhubung dengan sistem distribusi harus memenuhi standar yang sudah diatur dalam SNI. Untuk standar peralatan yang belum diatur dalam SNI, dapat mengacu pada standar internasional seperti ANSI, IEEE, NEC, NEMA, IEC atau mengacu pada standar yang ditetapkan oleh PLN (SPLN)[3].

Nilai data yang melebihi nilai standar, atau terindikasi akan menyebabkan pemborosan dianalisis lebih lanjut untuk mendapatkan nilai pemborosan energi yang dihasilkan. Setelah diketahui besar pemborosan daya yang dihasilkan, berikan rekomendasi untuk menghilangkan penyebab pemborosan energi tersebut disertai dengan perhitungan penghematan energi yang dihasilkan. Peralatan pemanfaat energi listrik juga dianalisa berdasarkan besar konsumsi 
daya, dan dibandingkan dengan peralatan subtitusi yang memiliki fungsi sama tetapi tingkat efisiensi konsumsi energi lebih tinggi.

Setelah penyebab pemborosan energi diketahui, penulis akan memberikan rekomendasi efisiensi energi berdasarkan masalah yang terjadi dan potensi efisiensi energi listrik yang ada.

\section{Hasil dan Analisa}

\subsection{Bauran Energi PT. SAI Apparel}

Berdasarkan data yang diperoleh, dapat disusun Tabel 1 bauran energi PT. SAI Apparel selama tahun 2016.

Tabel 1. Bauran Energi PT. SAI Apparel 2016

\begin{tabular}{lcc}
\hline $\begin{array}{c}\text { Sumber } \\
\text { Energi }\end{array}$ & $\begin{array}{c}\text { Satuan } \\
\text { (TOE) }\end{array}$ & Presentase \\
\hline Listrik & 650 & $13 \%$ \\
Batubara & 4.004 & $83 \%$ \\
Solar & 161 & $3 \%$ \\
Total & $\mathbf{4 . 8 1 5}$ & $\mathbf{1 0 0 \%}$ \\
\hline
\end{tabular}

Berdasarkan Tabel 1 diketahui selama tahun 2016 konsusmsi energi total yang digunakan oleh PT. SAI Apparel sebesar 4.815 TOE. Sumber energi paling besar yang digunakan adalah energi batubara, yaitu sebesar 4.004 TOE (83\%), energi listrik sebesar 650 TOE (13\%), dan yang paling kecil adalah energi solar, yaitu sebesar 161 TOE $(3 \%)$.

\subsection{Konsumsi Energi Spesifik}

Energi listrik yang digunakan oleh PT. SAI Apparel selama proses produksi terdiri dari energi listrik dari sumber PLN, dan dari genset. Maka dari itu konsumsi solar yang digunakan oleh genset harus dikonversikan menjadi kWh yang dihasilkan oleh genset. Genset akan membangkitkan daya sebesar kebutuhan beban dari sistem, dari data AMR diketahui konsusmi daya semu rata-rata PT. SAI Apparel selama jam kerja sebesar $1.946 \mathrm{kVA}$ dengan faktor daya 0,87. Perhitungan prakiraan energi listrik yang dibangkitkan oleh genset menggunakan perhitungan sebagai berikut[4].

$Q=k \cdot S_{A V G} \cdot \mathrm{t}$

Diketahui:

$$
\begin{aligned}
& k=0,21 \\
& S_{A V G}=1.946 \mathrm{kVA} \\
& \mathrm{T} \quad=1 \mathrm{jam} \\
& Q=0,21.1,946.1 \\
& Q=409 \text { liter } / \mathrm{jam}
\end{aligned}
$$

Setelah diketahui konsumsi solar setiap jam nya, dengan membagi konsumsi solar per bulan dengan konsumsi solar per jam akan diperoleh waktu operasi genset setiap bulannya. Berikut perhitungan menggunakan contoh data bulan januari 2016.

$$
\begin{aligned}
t_{\text {januari }} & =\frac{Q_{\text {januari }}}{Q} \\
& =\frac{15.157}{409} \\
& =37,09 \mathrm{jam}
\end{aligned}
$$

Energi listrik yang dibangkitkan oleh genset diperoleh dengan mengalikan daya rata-rata (Watt) yang dibangkitkan genset dengan waktu operasi genset.

$$
\begin{aligned}
k W h & =P_{\text {avg }} \cdot t_{\text {januari }} \\
& =1.692 \times 37,09 \\
& =62.754 \mathrm{kWh}
\end{aligned}
$$

Setelah diketahui besar kWh yang dibangkitkan genset, diketahui energi listrik total setiap bulannya. Dengan membagi konsumsi energi listrik total dengan jumlah produksi setiap bulan, diperoleh Tabel 2 KES PT. SAI Apparel sebagai berikut.

Tabel 2. KES PT. SAI Apparel 2016

\begin{tabular}{lccc}
\hline \multicolumn{1}{c}{ Bulan } & $\begin{array}{c}\text { Energi } \\
\text { Listrik Total } \\
\text { (kWH) }\end{array}$ & $\begin{array}{c}\text { Kapasitas } \\
\text { Produksi } \\
\text { (Potong) }\end{array}$ & KES (kWh/Potong) \\
\hline Januari & 638.994 & 1.487 .395 & 0,43 \\
Februari & 722.895 & 1.600 .737 & 0,45 \\
Maret & 664.148 & 1.400 .419 & 0,47 \\
April & 605.165 & 1.256 .763 & 0,48 \\
Mei & 759.372 & 1.208 .248 & 0,63 \\
Juni & 760.548 & 1.186 .215 & 0,64 \\
Juli & 709.720 & 662.145 & 1,07 \\
Agustus & 522.257 & 1.108 .317 & 0,47 \\
September & 663.580 & 1.020 .903 & 0,65 \\
Oktober & 682.828 & 1.061 .814 & 0,64 \\
November & 737.276 & 1.393 .442 & 0,53 \\
Desember & 842.979 & 1.387 .159 & 0,61 \\
\hline
\end{tabular}

Berdasarkan analisa Tabel 2 diketahui konsumsi energi spesifik PT. SAI Apparel selama tahun 2016 berkisar 0,43$1,07 \mathrm{kWh} /$ potong.

\subsection{Profil Beban PT. SAI Apparel}

Berdasarkan data AMR bulan Mei 2017 diketahui bahwa konsumsi daya semu maksimal sebesar $2.534 \mathrm{kVA}$. Untuk konsumsi daya semu maksimum memiliki nilai rata-rata sebesar 2.413kVA. PT. SAI Apparel berlangganan daya listrik ke PLN sebesar 2.770kVA, apabila ditinjau dari konsumsi daya semu maksimum masih terdapat cadangan kapasitas daya sebesar 236kVA (9\%).

\subsection{Pengguna Energi Signifikan (PES)}

Konsumsi energi listrik total PT. SAI Apparel selama tahun 2016 adalah 8.309.763kWh. Dengan pengukuran daya aktual pada beban didapatkan persentase konsumsi 
energi beban berdasarkan penggolongan beban PES dan non PES seperrti ditampilkan pada Tabel 3 sebagai berikut

Tabel 3. Pengguna Energi Signifikan PT. SAI Apparel

\begin{tabular}{lrr}
\hline \multicolumn{1}{c}{ Beban } & $\begin{array}{c}\text { Konsumsi Energi } \\
(\mathbf{k W h})\end{array}$ & Persentase \\
\hline Pendingin Ruangan & 531.700 & $6 \%$ \\
Kompresor Udara & 817.414 & $10 \%$ \\
Pencahayaan & 1.005 .309 & $12 \%$ \\
Motor & 4.302 .841 & $52 \%$ \\
& & \\
Total PES & $\mathbf{6 . 6 5 7 . 2 6 4}$ & $\mathbf{8 0 \%}$ \\
Total Non PES & $\mathbf{1 . 6 5 2 . 4 9 8}$ & $\mathbf{2 0 \%}$ \\
\hline
\end{tabular}

Beban PES didominasi oleh beban motor, yaitu sebesar $80 \%$, dilanjutkan beban pencahayaan $12 \%$, beban kompresor udara $10 \%$, dan beban pendingin ruangan $6 \%$ dari konsumsi energi listrik total selama tahun 2016. Selain beban PES terdapat beban non PES sebesar 20\% dari konsumsi energi listrik total tahun 2016.

\subsection{Efisiensi dan Faktor Pembebanan Transformator}

Efisiensi pada trafo dipengaruhi oleh nilai rugi besi dan rugi belitan. Rugi belitan pada trafo dipengaruhi oleh besar arus beban yang mengalir, sedangkan rugi besi nilainya tetap. Berikut adlaah contoh perhitungan efisiensi trafo substation 1 pada jam 08.00. Diketahui kapasitas trafo 1.600kVA; Rugi besi 2.200 Watt; dan Rugi belitan 19.000 Watt.

Tabel 4. Data pengukuran substation 1

\begin{tabular}{cccc}
\hline Daya (Watt) & Arus (A) & Tegangan (V) & $\operatorname{Cos} \boldsymbol{\theta}$ \\
\hline 611.352 & 1.108 & 362 & 0,88 \\
\hline
\end{tabular}

Menghitung arus beban penuh

$$
\begin{aligned}
I_{\text {full load }} & =\frac{S}{1,73 \cdot V} \\
& =\frac{1.600}{1,73 \times 362} \\
& =2.552 \mathrm{~A}
\end{aligned}
$$

Rugi belitan aktual[5]

$$
\begin{aligned}
P_{c u}^{\prime} & =\left(I_{\text {load }} / I_{\text {full load }}\right)^{2} \times P_{c u} \\
& =(1.108 / 2.552)^{2} \times 19.000 \\
& =3.582 \quad \text { Watt }
\end{aligned}
$$

Selanjutnya hitung efisiensi trafo, sebagai berikut

$$
\begin{aligned}
\eta & =\frac{P_{o}}{P_{o}+P_{\Sigma}} \times 100 \% \\
& =\frac{611.352}{611.352+3.582+2.200} \times 100 \% \\
& =99,06 \%
\end{aligned}
$$

Dengan cara yang sama diketahui efisiensi seluruh trafo yang dimiliki PT. SAI Apparel memiliki rata-rata diatas $98 \%$ pada variasi pembebanan $5,44 \%$ hingga $54,37 \%$. Nilai ini sudah sesuai dengan nilai rugi daya trafo distribusi pada SPLN D3.002-1;2007 dan SPLN 50 1997[6][7].

\subsection{Ketidakseimbangan Tegangan}

Berikut adalah contoh perhitungan untuk ketidakseimbangan tegangan MDP Hall A pada jam 12.55.

Tabel 5. Data tegangan MDP Hall A jam 12.55

\begin{tabular}{lllll}
\hline \multirow{2}{*}{ Jam } & \multicolumn{4}{c}{ Tegangan (V) } \\
& R-N & S-N & T-N & Rata-rata \\
\hline 12.55 .00 & 214,3 & 217,4 & 218,3 & 216,67 \\
\hline$\% V_{\text {unbalance }}$ & $=\frac{\text { deviasi maksimum }}{\text { Tegangan rata-rata }} \times 100 \%$ \\
& $=\frac{2,37}{216,67} \times 100 \%$ \\
& $=1,09 \%$
\end{tabular}

\begin{tabular}{|c|c|c|c|c|}
\hline \multirow{2}{*}{ Jam } & \multicolumn{4}{|c|}{ Arus (A) } \\
\hline & $\mathbf{R}$ & $S$ & $\mathrm{~T}$ & Rata-rata \\
\hline 12.55 .00 & 456,9 & 430,7 & 401,4 & 429,67 \\
\hline$\% I_{\text {unbalance }}$ & \multicolumn{4}{|c|}{$\begin{array}{l}=\frac{\text { deviasi maksimum }}{\text { Arus rata-rata }} \times 100 \% \\
=\frac{28,27}{429,67} \times 100 \%\end{array}$} \\
\hline
\end{tabular}

Dengan cara yang sama diketahui nilai ketidakseimbangan tegangan rata-rata pada MDP Hall A, B, dan C tidak sesuai dengan standar NEMA MG 1, yaitu sebesar 1\%[8].

\subsection{Ketidakseimbangan Arus}

Berikut adalah contoh perhitungan untuk ketidakseimbangan tegangan MDP Hall A pada jam 12.55

Tabel 6. Data arus MDP Hall A jam 12.55

Dengan cara yang sama diketahui nilai ketidakseimbangan arus rata-rata pada MDP Hall B dan C tidak sesuai dengan standar NEMA MG 1, yaitu sebesar 10\%[8].

\subsection{Faktor Daya}

PT. SAI Apparel tercatat beberapa kali terkena penalti kVARH, yaitu pada bulan November 2016 hingga Januari 2017. Kondisi ini mengidentifikasikan bahwa nilai faktor daya rata-rata PT. SAI Apparel pada bulan tersebut dibawah 0,85. Berdasarkan pengamatan data AMR tanggal 10 hingga 16 Juli 2016, diketahui nilai faktor daya rata-rata PT. SAI Apparel 0,84. Nilai ini berada sedikit dibawah batas kVARH yaitu 0,85 [9]. 
Dalam pengamatan faktor daya pada masing-masing substation diketahui faktor daya rata-rata masing-masing substation sebagai berikut

\section{Tabel 7. Faktor daya rata-rata substation}

\begin{tabular}{cccc}
\hline \multicolumn{4}{c}{ Substation } \\
$\mathbf{1}$ & $\mathbf{2}$ & $\mathbf{3}$ & $\mathbf{4}$ \\
\hline 0,85 & 0,86 & 0,83 & 0,98 \\
\hline
\end{tabular}

Berdasarkan Tabel 7 diketahui nilai faktor daya paling rendah terdapat pada substation 3 , yaitu 0,83 . Faktor daya rata-rata substation 1 dan 2 berkisar 0,85 . Faktor daya paling bagus terdapat pada substation 4, yaitu 0,98 . Kondisi ini diakibatkan oleh kondisi kapasitor bank yang berfungsi hanya pada substation 4 .

\subsection{Susut Tegangan}

Karena jumlah SDP yang terlalu banyak, nilai drop tegangan diukur antara tagngan di sisi MDP dengan sample SDP terjauh, dan antara SDP dengan titik beban terjauh. Berikut adlah contoh perhitungan susut tegangan Hall A pada jam 14.30.

Tabel 8. Pengukuran tegangan pada MDP dan SDP

\begin{tabular}{ccccc}
\hline Hall & Fasa & MDP & SDP & $\begin{array}{c}\text { Susut } \\
\text { Tegangan }\end{array}$ \\
\hline \multirow{2}{*}{$\mathrm{A}$} & $\mathrm{R}$ & 372 & 369 & $0,81 \%$ \\
& $\mathrm{~S}$ & 376 & 374 & $0,53 \%$ \\
& $\mathrm{~T}$ & 373 & 371 & $0,54 \%$ \\
\hline
\end{tabular}

Susut tegangan fasa $\mathrm{R}$

$$
\begin{aligned}
\% \text { Drop Voltage } & =\frac{\Delta V}{V t} \times 100 \% \\
& =\frac{369}{372} \times 100 \% \\
& =0,81 \%
\end{aligned}
$$

Susut tegangan fasa $\mathrm{S}$

$$
\begin{aligned}
\% \text { Drop Voltage } & =\frac{\Delta V}{V t} \times 100 \% \\
& =\frac{374}{376} \times 100 \% \\
& =0,53 \%
\end{aligned}
$$

Susut tegangan fasa $\mathrm{T}$

$$
\begin{aligned}
\% \text { Drop Voltage } & =\frac{\Delta V}{V t} \times 100 \% \\
& =\frac{371}{373} \times 100 \% \\
& =0,54 \%
\end{aligned}
$$

Dengan cara yang sama diperoleh nilai susut tegangan pada seluruh substation dari MDP hingga ke beban. Berdasarkan data perhitungan diketahui bahwa persen susut tegangan di PT. SAI Apparel tidak ada yang melebihi nilai standar pada PUIL 2000.

\subsection{DHT Tegangan dan DHT Arus}

Nilai DHT tegangan di PT. SAI Apparel berdasarkan hasil pengambilan data ditunjukan pada Tabel 9.

\begin{tabular}{|c|c|c|c|c|c|}
\hline \multirow[t]{2}{*}{ Terminal Ukur } & \multirow[t]{2}{*}{$\mathrm{Isc} / \mathrm{IL}_{\mathrm{L}}$} & \multicolumn{3}{|c|}{ THD i (\%) } & \multirow{2}{*}{$\begin{array}{c}\text { Standar } \\
(\%)\end{array}$} \\
\hline & & $\mathrm{R}-\mathrm{N}$ & S-N & $\mathrm{T}-\mathrm{N}$ & \\
\hline MDP Hall A & 94,11 & 6,33 & 6,59 & 8,14 & 12 \\
\hline MDP Hall B & 83,20 & 6,40 & 6,65 & 8,17 & 12 \\
\hline MDP Hall C & 58,68 & 5,30 & 5,17 & 4,42 & 12 \\
\hline $\begin{array}{c}\text { MDP Polybag \& } \\
\text { Karton }\end{array}$ & 260,3 & 9,28 & 11,2 & 12,2 & 15 \\
\hline $\begin{array}{c}\text { LVMDP } \\
\text { Substation } 3\end{array}$ & 58,70 & 9,24 & 8,26 & 8,85 & 12 \\
\hline $\begin{array}{c}\text { LVMDP } \\
\text { Substation } 4\end{array}$ & 56,57 & 8,10 & 8,26 & 9,13 & 12 \\
\hline
\end{tabular}

Tabel 9. Rata-rata DHT Tegangan PT. SAI Apparel

\begin{tabular}{ccccc}
\hline Terminal Ukur & R-N & $\begin{array}{c}\text { THD v (\%) } \\
\text { S-N }\end{array}$ & T-N & $\begin{array}{c}\text { Standar } \\
(\%)\end{array}$ \\
\hline MDP Hall A & 2,30 & 2,11 & 1,97 & 5 \\
MDP Hall B & 2,18 & 1,98 & 1,81 & 5 \\
MDP Hall C & 2,06 & 1,60 & 1,57 & 5 \\
$\begin{array}{c}\text { MDP Polybag \& } \\
\text { Karton }\end{array}$ & 2,00 & 1,56 & 1,43 & 5 \\
$\begin{array}{c}\text { LVMDP Substation 3 } \\
\text { MV }\end{array}$ & 1,34 & 1,40 & 1,39 & 5 \\
LVMP Substation 4 & 2,24 & 2,23 & 2,52 & 5 \\
\hline
\end{tabular}

Berdasarkan Tabel 9 nilai DHT tegangan di seluruh substation masih memenuhi nilai standar SPLN D5.0041:2012. Selanjutnya nilai DHT arus akan ditampilkan pada Tabel 10

Tabel 10. Rata-rata DHT Arus PT. SAI Apparel

Nilai THD arus PT. SAI Apparel masih memenuhi nilai standar pada SPLN D5.004-1:2012, yaitu sesuai tercantum di Tabel 10.

\subsection{Peluang Efisiensi Energi}

Berdasarkan analisis dari data yang telah diolah didapatkan beberapa potensi penghematan energi, yaitu:

1. Penyeimbangan beban masing-masing fasa untuk mereduksi ketidakseimbangan tegangan dan ketidakseimbangan arus

2. Penggunaan peralatan hemat energi

3. Perbaikan faktor daya dengan penambahan kapasitas kapasitor bank pada substation 1, 2 dan 3 
TRANSIENT, VOL. 7, NO. 1, MARET 2018, ISSN: 2302-9927, 53

\subsection{Penyeimbangan Beban Pada Fasa $R, S$, dan $T$}

Ketidakseimbangan pembebanan antara fasa R,S, dan T mengakibatkan tingginya ketidakseimbangan arus dan tegangan pada sistem tenaga listrik di PT. SAI Apparel. Ketidakseimbangan arus mengakibatkan timbulnya arus pada penghantar netral, besar arus yang timbul dihitung sebagai berikut dengan contoh data arus MDP Hall A pada jam 12.55 .

\section{Diketahui:}

Sudut fasa $I_{R} \quad=30,78$

Sudut fasa $\mathrm{I}_{\mathrm{S}} \quad=151,32$

Sudut fasa $\mathrm{I}_{\mathrm{T}} \quad=268,83$

$$
\begin{aligned}
I_{N} & =I_{R}+I_{S}+I_{T} \\
& =456,9 \angle 30,8+430,7 \angle 151,3+401,4 \angle 268,8 \\
& =39,7 \mathrm{~A}
\end{aligned}
$$

Dengan cara yang sama diperoleh besar arus netral pada

\begin{tabular}{|c|c|c|c|}
\hline Terminal Ukur & Kondisi & Unb Arus & Arus Netral (A) \\
\hline MDP Hall A & $\begin{array}{l}\text { Maksimum } \\
\text { Minimum } \\
\text { Rata-rata }\end{array}$ & $\begin{array}{c}14,94 \% \\
3,24 \% \\
8,87 \%\end{array}$ & $\begin{array}{c}101,72 \\
36,06 \\
64,56\end{array}$ \\
\hline MDP Hall B & $\begin{array}{l}\text { Maksimum } \\
\text { Minimum } \\
\text { Rata-rata }\end{array}$ & $\begin{array}{c}17,12 \% \\
7,37 \% \\
12,23 \%\end{array}$ & $\begin{array}{l}94,65 \\
12,12 \\
52,93\end{array}$ \\
\hline MDP Hall C & $\begin{array}{l}\text { Maksimum } \\
\text { Minimum } \\
\text { Rata-rata }\end{array}$ & $\begin{array}{c}19,63 \% \\
9,73 \% \\
14,21 \%\end{array}$ & $\begin{array}{l}207,44 \\
133,37 \\
162,94\end{array}$ \\
\hline $\begin{array}{l}\text { MDP Polybag \& } \\
\quad \text { Karton }\end{array}$ & $\begin{array}{l}\text { Maksimum } \\
\text { Minimum } \\
\text { Rata-rata }\end{array}$ & $\begin{array}{c}16,81 \% \\
2,92 \% \\
9,00 \%\end{array}$ & $\begin{array}{l}37,54 \\
12,66 \\
19,63\end{array}$ \\
\hline LVMDP Substation 3 & $\begin{array}{l}\text { Maksimum } \\
\text { Minimum } \\
\text { Rata-rata }\end{array}$ & $\begin{array}{l}8,75 \% \\
4,19 \% \\
6,84 \%\end{array}$ & $\begin{array}{l}57,85 \\
50,05 \\
55,33\end{array}$ \\
\hline LVMDP Substation 4 & $\begin{array}{l}\text { Maksimum } \\
\text { Minimum } \\
\text { Rata-rata }\end{array}$ & $\begin{array}{c}12,90 \% \\
2,98 \% \\
7,98 \%\end{array}$ & $\begin{array}{c}131,87 \\
21,52 \\
74,97\end{array}$ \\
\hline
\end{tabular}
LVMDP dan MDP PT. SAI Apparel pada Tabel 10

Tabel 11 Tabel Perhitungan Arus netral

Arus netral ini akan menambah rugi daya $I^{2} R$ sepanjang penghantar netral. Arus netral dapat diminimalisir dengan penyeimbangan beban antar fasa.

\subsection{Penggunaan Peralatan Hemat Energi}

Peralatan hemat energi yang direkomendasikan dalam penelitian ini adalah dengan penggantian mesin jahit motor induksi dengan motor servo, dan penggantian lampu TL Fluorescent 36 Watt dengan lampu LED 16 Watt. Hasil pengukuran daya aktual pada mesin jahit dengan motor induksi dan motor servo ditunjukan pada Tabel 12.
Tabel 12 Hasil pengukuran daya aktual motor induksi dan servo

\begin{tabular}{llcccr}
\hline \multirow{2}{*}{ Tipe } & \multirow{2}{*}{ Kondisi } & \multicolumn{2}{c}{ Daya $(\mathbf{k W})$} & \multicolumn{2}{c}{ Faktor Daya } \\
& & Induksi & Servo & Induksi & Servo \\
\hline \multirow{2}{*}{ SNLS } & Dibebani & 0,391 & 0,127 & 0,80 & 0,56 \\
& Standby & 0,090 & 0,019 & 0,30 & 0,46 \\
DNLS & Dibebani & 0,372 & 0,109 & 0,84 & 0,67 \\
& Standby & 0,100 & 0,013 & 0,33 & 0,65 \\
\multirow{2}{*}{ Overlock } & Dibebani & 0,274 & 0,264 & 0,84 & 0,64 \\
& Standby & 0,068 & 0,011 & 0,45 & 0,45 \\
\hline
\end{tabular}

Berdasarkan data pengukuran pada Tabel 12 dapat dicari konsumsi energi total seluruh motor yang sekarang terpasang dan konsumsi energi apabila seluruh mesin jahit menggunakan motor servo. Berikut adalah perhitungan penghematan energi yang dihasilkan.

$$
\begin{aligned}
\text { Energy Saving } & =k W h \text { lama }-k W h \text { baru } \\
& =1.001 .268-385.045 \\
& =616.223 \mathrm{kWh}
\end{aligned}
$$

Dengan penggantian mesin jahit motor induksi dengan motor servo pada tipe motor SNLS, DNLS, dan Overlock didapatkan nilai penghematan energi listrik sebesar $616.223 \mathrm{kWh} /$ tahun. Selain penggantian motor dengan yang jenis motor yang lebih hemat energi, rekomendasi serupa dapat diterapkan pada beban lampu. Data pengukuran konsumsi daya pada lampu TL 36 Watt dan LED 16 Watt ditunjukan pada Tabel 13.

Tabel 13 Hasil Pengukuran daya lampu TL dan LED

\begin{tabular}{ccccc}
\hline $\begin{array}{c}\text { Terminal } \\
\text { Pengukuran }\end{array}$ & \multicolumn{2}{c}{ Jumlah Lampu } & Cose & $\begin{array}{c}\text { Daya } \\
\text { Pengukuran (W) }\end{array}$ \\
\hline Line 2 kiri & 28 & 0 & 0,96 & 840 \\
Line 1 kiri & 12 & 16 & 0,91 & 630 \\
Line 2 kanan & 26 & 0 & 0,96 & 850 \\
Line 1 kanan & 12 & 14 & 0,91 & 620 \\
\hline
\end{tabular}

Berdasarkan hasil pengukuran tersebut diketahui konsumsi daya rata-rata satu TL adalah 31,35 Watt dan untuk lampu LED 16,57 Watt. Dengan penggantian lampu TL menjadi lampu LED akan diperoleh penghematan energi seperti pada perhitungan berikut.

$$
\begin{aligned}
\text { Penurunan Daya } & =P_{\text {lama }}-P_{\text {baru }} \\
& =379,915-200,828 \\
& =179,087 \mathrm{~kW}
\end{aligned}
$$

Penghematan energi yang dihasilkan merupakan hasil perkalian penurunan daya yang dihasilkan dengan hari operasi dan jam operasi selama satu tahun.

$$
\begin{aligned}
\text { Penghematan Energi } & =179,087 \times 279 \times 9 \\
& =449.687 \mathrm{kWh} / \text { tahun }
\end{aligned}
$$

Dengan konsumsi energi yang lebih hemat, lampu LED memiliki nilai LUX terukur yang setara dengan lampu TL 
36Watt. Hasil pengukuran LUX pada lampu TL dan LED ditunjukan pada Tabel 14.

Tabel 14 Hasil pengukuran LUX lampu LED dan TL

\begin{tabular}{llcc}
\hline $\begin{array}{c}\text { Jenis } \\
\text { Lampu }\end{array}$ & $\begin{array}{c}\text { Tempat } \\
\text { Pengukuran }\end{array}$ & $\begin{array}{c}\text { Jarak } \\
\text { Lampu (m) }\end{array}$ & $\begin{array}{c}\text { Kuat Pencahayaan } \\
\text { (Lux) }\end{array}$ \\
\hline TL 36 Watt & Depan meja & 1,5 & 955 \\
& Samping meja & 1,45 & 861 \\
LED 16 & Depan meja & 1,5 & 936 \\
Watt & Samping meja & 1,45 & 892 \\
\hline
\end{tabular}

\subsection{Perbaikan Faktor Daya}

Berdasarkan hasil pengukuran diketahui nilai faktor daya pada substation 1,2 , dan 3 nilainya berkisar pada 0,85 , maka dari itu perlu dilakukan perbaikan faktor daya untuk menghindari pinalty kVARH dan meminimalisir rugi daya yang terjadi. Berikut adalah contoh perhitungan penentuan kapasitas kapasitor bank untuk perbaikan faktor daya pada substation 1.

Diketahui :

$$
\begin{aligned}
& \mathrm{PF}_{1} \quad=0,88 \\
& \mathrm{PF}_{2} \quad=0,98 \\
& \mathrm{P}_{\text {sub } 1} \quad=627.861 \mathrm{Watt} \\
& \begin{aligned}
Q_{c} & =P\left[\tan \left(\cos ^{-1} P F_{1}\right)-\tan \left(\cos ^{-1} P F_{2}\right)\right] \\
& =627.861\left[\tan \left(\cos ^{-1} 0,88\right)-\tan \left(\cos ^{-1} 0,98\right)\right. \\
& =627.861(\tan 28,36-\tan 11,48) \\
& =
\end{aligned} 211,39 \mathrm{kVAR}
\end{aligned}
$$

Dengan cara yang sama didapatkan kapasitas kapasitor bank yang dibutuhkan untuk perbaikan faktor daya pada substation 2 dan 3, ditunjukan pada Tabel 15 sebagai berikut:

Tabel 15 Hasil perhitungan kebutuhan kapasitas kapasitor bank

\begin{tabular}{ccccc}
\hline Substation & $\mathbf{P F}_{1}$ & $\mathbf{P F}_{2}$ & $\mathbf{P}(\mathbf{k W})$ & $\mathbf{Q c}(\mathbf{k V A R})$ \\
\hline 1 & 0,88 & 0,98 & 627,86 & 211,39 \\
2 & 0,86 & 0,98 & 282,85 & 110,39 \\
3 & 0,83 & 0,98 & 466,31 & 218,67 \\
\hline
\end{tabular}

Kapasitor bank menghasilkan sejumlah kebutuhan daya reaktif untuk beban, maka jumlah daya reaktif yang ditransfer jaringan PLN ke pelanggan akan berkurang. Kondisi ini mengakibatkan besar arus yang mengalir dari titik sambung PLN hingga ke LVMDP tempat pemasangan kapasitor bank akan berkurang, maka rugi penghantar $I^{2} R$ sepanjang saluran tersebut juga akan berkurang. Berikut adalah penurunan rugi daya dan penghematan energi yang dihasilkan dengan perbaikan faktor daya.

$$
\begin{aligned}
\text { Reduksi rugi daya } & =\text { Rugi daya lama }- \text { Rugi daya baru } \\
& =22.646,67-20.346,99 \\
& =2.299,68 \mathrm{Watt}
\end{aligned}
$$

Penghematan energi yang dihasilkan didapatkan dengan mengalikan reduksi rugi daya, dengan hari operasi, dan jam operasi harian selama satu tahun.

$$
\begin{aligned}
\text { Penghematan Energi } & =2.299,68 \times 279 \times 9 \\
& =5.774,5 \mathrm{kWh} / \text { tahun }
\end{aligned}
$$

\section{Kesimpulan}

Berdasarkan analisis yang telah dilakukan pada penelitian ini dapat diambil beberapa kesimpulan, yaitu selama tahun 2016 PT. SAI Apparel menggunakan energi sebesar 4.815 yang memiliki bauran energi batubara $(83,15 \%)$, listrik $(13,5 \%)$, dan solar $(3,35 \%)$. Konsumsi energi listrik PT. SAI Apparel selama tahun 2016 adalah sebesar 8.309.763 kWh yang dikonsumsi oleh beban PES dan beban non PES. Beban PES terdiri dari beban motor $(52 \%)$, pencahayaan $(12 \%)$, kompresor $(10 \%)$ dan pendingin ruangan $(6 \%)$. Beban non PES terdiri dari beban peralatan kantor, dan beban rumah tangga yang tidak terkait dengan proses produksi, yaitu sebesar $20 \%$. Konsumsi energi spesifik PT. SAI Apparel selama tahun 2016 berada pada kisaran 0,43$1,07 \mathrm{kWh} /$ potong, dengan nilai rata-rata $0,59 \mathrm{kWh} /$ potong. Kemudian nilai KES rata-rata tersebut dijadikan sebagai baseline untuk evaluasi KES pada tahun-tahun berikutnya. Terdapat beberapa nilai kualitas daya listrik yang berada dibawah nilai standar yang berlaku, yaitu ketidakseimbangan tegangan dan ketidakseimbangan arus. Kondisi ini dapat diminimalisir dengan penyeimbangan beban pada masing-masing fasa. Nilai faktor daya pada substation 1,2 dan 3 juga berkisar pada 0,85, dengan perbaikan faktor daya akan dihasilkan penghematan energi sebesar 5.774,5kWh/tahun. Selain pada kualitas daya listrik terdapat potensi penghematan energi listrik dengan penggunaan peralatan hemat energi. Penggantian peralatan hemat energi tersebut berupa mengganti mesin jahit motor induksi menggunakan motor servo, menghasilkan penghematan energi sebesar $616.223 \mathrm{kWh} /$ tahun. Mengganti lampu TL 36 Watt menggunakan lampu LED 16 Watt menghasilkan penghematan energi sebesar 449.687kWh/tahun.

\section{Referensi}

[1] Dewan Energi Nasional, Ketahanan Energi Indonesia 2015. Jakarta Selatan, 2015.

[2] Pemerintah Republik Indonesia, "Peraturan Pemerintah Republik Indonesia no 70 Tahun 2009" 2009.

[3] Kementerian ESDM, "Peraturan Menteri ESDM No 04 Tahun 2009" 2009.

[4] S. Graha, "Power Management PLN-GENSET Pada Bank Indonesia Cabang Banjarmasin," 2014.

[5] C. W. T. McLyman, Transformer and Inductor Design Handbook. 2004.

[6] S. T. Distribusi, T. F. Tiga, and T. F. Tunggal, "Pt pln (persero) spln d3.002-1: 2007," no. 161, 2007.

[7] PT. PLN (Persero), "SPLN 50: 1997 Tentang Spesifikasi Transformator Distribusi," 1997.

[8] ANSI/NEMA, MG 1-2003 Motors and Generators. 